\title{
Thoracoscopic resection of bulky thymoma assisted with artificial pneumothorax: A report of 19 consecutive cases
}

\author{
MIAO ZHANG, HENG WANG, XUEFENG PAN, WENBIN WU and HUI ZHANG \\ Department of Thoracic Surgery, Xuzhou Central Hospital Affiliated to \\ Southeast University, Xuzhou, Jiangsu 221009, P.R. China
}

Received January 29, 2016; Accepted March 10, 2016

DOI: $10.3892 / \mathrm{ol} .2016 .4326$

\begin{abstract}
The aim of the present study was to examine the feasibility and efficacy of thoracoscopic radical resection of large retrosternal thymoma using artificial pneumothorax. A retrospective analysis was performed on 19 patients with bulky thymoma who underwent thoracoscopic resection using artificial pneumothorax by $\mathrm{CO}_{2}$ insufflation. The operations were performed with unilateral or bilateral thoracic incisions via single lumen endotracheal intubation and two-lung ventilation. This approach provided excellent exposure of the thoracic cavity and reliable control of the neuro-vascular structures in the anterior mediastinum, which was of vital importance for the extended resection of malignant thymoma. The operation time was $140.0 \pm 51.4$ min without conversion to thoracotomy or sternotomy. The pathological diagnosis was confirmed by immunohistochemistry, including 5 cases of thymus lipomyoma, 1 case of thymus hyperplasia, 1 case of thymus cyst, 2 cases of type AB thymoma, 4 cases of type B1 thymoma, 4 cases of type B3 thymoma, and 2 cases of thymic carcinoma. Furthermore, there were no complications such as recurrent laryngeal nerve injury, phrenic nerve injury, pulmonary infection or atelectasis, with a hospital stay of 5.0 \pm 3.0 days. In conclusion, the thoracoscopic resection of thymoma using artificial pneumothorax is a preferable approach, that may be considered for patients with bulky retrosternal tumors.
\end{abstract}

\section{Introduction}

Thymectomy was considered as the only curative treatment for patients with resectable thymoma (1). Landreneau et al introduced video-assisted thoracoscopic surgery (VATS) thymectomy in 1992 (2).

Correspondence to: Dr Hui Zhang, Department of Thoracic Surgery, Xuzhou Central Hospital Affiliated to Southeast University, 199 Jiefang South Road, Xuzhou, Jiangsu 221009, P.R. China

E-mail: qmlljlrgyr296@163.com

Key words: artificial pneumothorax, two-lung ventilation, thymoma
Double-lumen endotracheal tube (DLET) anesthesia is the routine method for VATS thymectomy, which may frequently result in more complications (3). In rare circumstances, use of the single-lumen endotracheal tube (SLET) is mandatory, such as the translocation of the DLET, structural malformations, and tracheostenosis (4). Double-lung ventilation with SLET intubation potentially offers improved visualization for certain thoracoscopic procedures (5).

In the present study, we retrospectively examined SLET anaesthesia with $\mathrm{CO}_{2}$ insufflation artificial pneumothorax in VATS thymectomy to determine whether patients benefit from this type of surgery.

\section{Patients and methods}

Patients. In total, 19 patients with bulky thymoma underwent thoracoscopic resection assisted with artificial pneumothorax via $\mathrm{CO}_{2}$ insufflation at the Xuzhou Central Hospital (Jiangsu, China), between January 2014 and April 2015 by the same surgeon. The study was approved by the Institutional Review Board of Xuzhou Central Hospital. Informed consent regarding participation was received from the patients.

Methods. During the procedure, the patients were placed in a supine position with double-lung ventilation. Firstly, the thoracoscopy was placed into the thorax for exploration, and pleural adhesions were separated carefully using an ultrasonic scalpel (Johnson \& Johnson, NY, USA). Artificial $\mathrm{CO}_{2}$ pneumothorax $\left(\mathrm{CO}_{2}\right.$ pressure $\left.=8 \mathrm{mmHg}\right)$ was then established. Three to four ports were made with respect to the location and the size of the lesion determined by CT (Fig. 1). Generally, the thoracoscopic thymectomy was performed following the procedures detailed by other surgeons previously (6). The dissection was initiated with the inferior thymic poles carefully mobilized. Subsequently, the anterior mediastinal tissue was swept along the pericardium and the retrosternum. The innominate vein was located at the junction with the superior vena cava, and dissection continued until the thymic vein was located, which was then doubly clipped. The operation was completed by dissecting directly along the left pleura to avoid injury to the left phrenic nerve. One of the manipulating ports was enlarged appropriately for the extraction of thymus, and a drainage tube was placed unilaterally. 


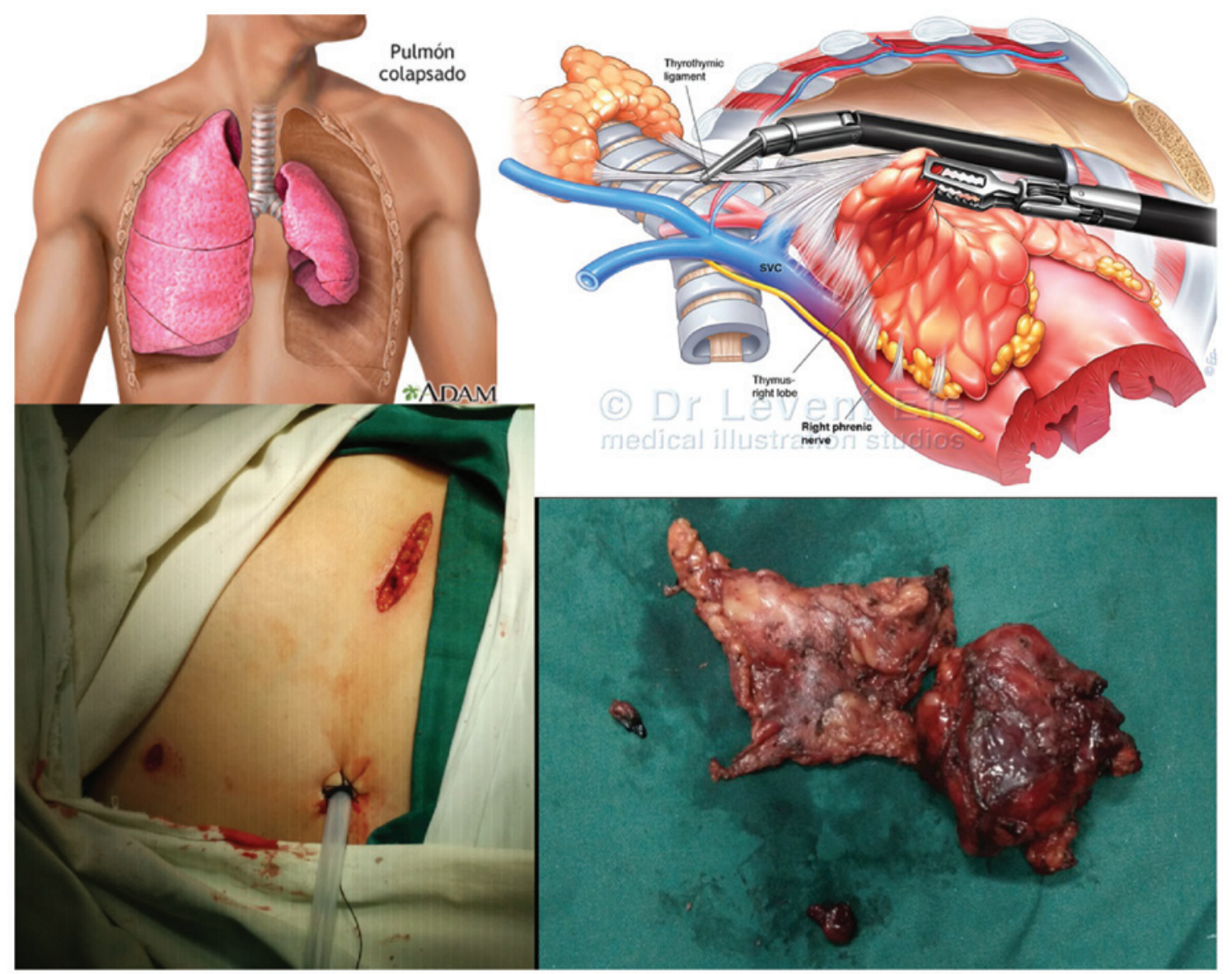

Figure 1. The graphs with $\mathrm{CO}_{2}$ insufflations during the VATS thymectomy. VATS, video-assisted thoracoscopic surgery.

\section{Results}

The operations were performed with unilateral or bilateral thoracic incisions via single-lumen endotracheal intubation and double-lung ventilation. This approach provided excellent exposure of the thoracic cavity and reliable control of the neuro-vascular structures in the anterior mediastinum. This was crucial for the extended resection of malignant thymoma. The operation time was $140.0 \pm 51.4$ min without conversion to thoracotomy or sternotomy. The pathological diagnosis was confirmed by immunohistochemistry resulting in, 5 cases of thymus lipomyoma, 1 case of thymus hyperplasia, 1 case of thymus cyst, 2 cases of type AB thymoma, 4 cases of type B1 thymoma, 4 cases of type B3 thymoma, and 2 cases of thymic carcinoma. Furthermore, there were no complications such as recurrent laryngeal nerve injury, phrenic nerve injury, pulmonary infection or atelectasis. The patients had a hospital stay of 5.0 \pm 3.0 days.

\section{Discussion}

The application of VATS thymectomy was extended with advances in techniques. VATS thymectomy is optimal compared with the open approach for early-stage thymoma patients (Masaoka staging I-II), which indicated shorter postoperative hospital length of stay (5.26 vs. 8.32 days), less blood loss (114.74 vs. $194.51 \mathrm{ml}$ ) and shorter duration of postoperative drainage (3.87 vs. 5.22 days), respectively (6). Similarly, it was reported that VATS thymectomy showed less postoperative complications with similar 5-year overall survival, 5 -year disease-free survival and recurrence rates $(7,8)$. The superior poles of the thymus may be exposed by $\mathrm{CO}_{2}$ insufflation and neck flexion, without cervical incision (9). In addition, Suda et al reported that single-port trans-subxiphoid robotic thymectomy assisted with $\mathrm{CO}_{2}$ gas injection at $8 \mathrm{mmHg}$ provides a good operative view in the neck region and makes verification of the phrenic nerve easy (10). Furthermore, Wu et al reported that uniportal VATS for mediastinal tumour resection including extended thymectomy was a promising and safe technique (11).

Notably, the size of the thymoma was not an absolute contraindication for VATS, because the thymoma with maximal diameter of $\sim 13 \mathrm{~cm}$ was completed through the VATS approach, as previously reported (6). Furthermore, DLET and one-lung ventilation may result in a variety of complications, including hoarseness, hypoxaemia, tracheobronchial injury, vocal cord injury and re-expansion or oxidative stress $(12,13)$. Therefore, $\mathrm{CO}_{2}$ infusion artificial pneumothorax with double-lung ventilation may be a better option for VATS (4). Of note the artificial pneumothorax is not suitable for all cases, and DLET should be prepared in case the need of single-lung ventilation during the surgery, such as severe pleural adhesion to avoid pleural tear and bleeding, is required. In addition, the artificial pneumothorax with $\mathrm{CO}_{2}$ insufflation may result in deteriorative changes, such as circulatory failure, ventricular arrhythmias and contralateral pneumothorax. This should be 
considered during the surgery assisted with artificial pneumothorax. However, a moderate-to-low intra-abdominal pressure $>12 \mathrm{mmHg}$ can assist to limit the extent of the pathophysiological changes (14). Brock et al reported that one-lung ventilation via a double-lumen endotracheal tube is safe and convenient for VATS surgery (15). In conclusion, our initial experience of 19 cases indicated that VATS thymectomy assisted with artificial pneumothorax via single-lumen endotracheal intubation and two-lung ventilation is safe and feasible, and constitutes a method that may be utilized for patients with other retrosternal tumors.

\section{Acknowledgements}

The simulated graphs of pneumothorax and VATS procedure were obtained from https://images.search.yahoo.com, for which we extend thanks to the original authors.

\section{References}

1. Detterbeck FC and Zeeshan A: Thymoma: current diagnosis and treatment. Chin Med J (Engl) 126: 2186-2191, 2013.

2. Landreneau RJ, Dowling RD, Castillo WM and Ferson PF: Thoracoscopic resection of an anterior mediastinal tumor. Ann Thorac Surg 54: 142-144, 1992.

3. Cerfolio RJ, Bryant AS, Sheils TM, Bass CS and Bartolucci AA Video-assisted thoracoscopic surgery using single-lumen endotracheal tube anesthesia. Chest 126: 281-285, 2004.

4. Zhang R, Liu S, Sun H, Liu X, Wang Z, Qin J, Hua X and Li Y: The application of single-lumen endotracheal tube anaesthesia with artificial pneumothorax in thoracolaparoscopic oesophagectomy. Interact Cardiovasc Thorac Surg 19: 308-310, 2014.

5. Cheng YL, Huang TW, Lee SC, Wu CT, Chen JC, Chang H and Tzao C: Video-assisted thoracoscopic surgery using single-lumen endotracheal tube anaesthesia in primary spontaneous pneumothorax. Respirology 15: 855-859, 2010.
6. Yuan ZY, Cheng GY, Sun KL, Mao YS, Li J, Wang YG, Wang DL, Gao SG, Xue Q, Huang JF, et al: Comparative study of video-assisted thoracic surgery versus open thymectomy for thymoma in one single center. J Thorac Dis 6: 726-733, 2014.

7. Manoly I, Whistance RN, Sreekumar R, Khawaja S, Horton JM, Khan AZ, Casali G, Thorpe JA, Amer K and Woo E: Early and mid-term outcomes of trans-sternal and video-assisted thoracoscopic surgery for thymoma. Eur J Cardiothorac Surg 45: e187-e193, 2014.

8. Liu TJ, Lin MW, Hsieh MS, Kao MW, Chen KC, Chang CC, Kuo SW, Huang PM, Hsu HH, Chen JS, et al: Video-assisted thoracoscopic surgical thymectomy to treat early thymoma: a comparison with the conventional transsternal approach. Ann Surg Oncol 21: 322-328, 2014.

9. Lee CY, Kim DJ, Lee JG, Park IK, Bae MK and Chung KY: Bilateral video-assisted thoracoscopic thymectomy has a surgical extent similar to that of transsternal extended thymectomy with more favorable early surgical outcomes for myasthenia gravis patients. Surg Endosc 25: 849-854, 2011.

10. Suda T, Tochii D, Tochii S and Takagi Y: Trans-subxiphoid robotic thymectomy. Interact Cardiovasc Thorac Surg 20: 669-671, 2015.

11. Wu CF, Gonzalez-Rivas D, Wen CT, Liu YH, Wu YC, Chao YK, Heish MJ, Wu CY and Chen WH: Single-port video-assisted thoracoscopic mediastinal tumour resection. Interact Cardiovasc Thorac Surg 21: 644-649, 2015.

12. Misthos P, Katsaragakis S, Milingos N, Kakaris S, Sepsas E, Athanassiadi K, Theodorou D and Skottis I: Postresectional pulmonary oxidative stress in lung cancer patients. The role of one-lung ventilation. Eur J Cardiothorac Surg 27: 379-382, discussion 382-383, 2005.

13. Knoll H, Ziegeler S, Schreiber JU, Buchinger H, Bialas P, Semyonov K, Graeter T and Mencke T: Airway injuries after one-lung ventilation: a comparison between double-lumen tube and endobronchial blocker: a randomized, prospective, controlled trial. Anesthesiology 105: 471-477, 2006.

14. Gutt CN, Oniu T, Mehrabi A, Schemmer P, Kashfi A, Kraus T and Büchler MW: Circulatory and respiratory complications of carbon dioxide insufflation. Dig Surg 21: 95-105, 2004.

15. Brock H, Rieger R, Gabriel C, Pölz W, Moosbauer W and Necek S: Haemodynamic changes during thoracoscopic surgery the effects of one-lung ventilation compared with carbon dioxide insufflation. Anaesthesia 55: 10-16, 2000. 